\title{
Penyusunan Peta Kondisi Klimatologi Dan Hidrologi Dalam Upaya Pemanfaatan Kondisi Lingkungan Desa Cintaratu, Kab. Pangandaran
}

\section{Preparation of Climatology and Hydrology Conditions Map in an Effort to Utilize Environmental Conditions in Cintaratu Village, Pangandaran District}

\author{
Hendi Setiyatwan ${ }^{1)}$, Novi Mayasari ${ }^{1)}$, M. Rifqi Ismiraj ${ }^{2)^{*}}$, Indah Kurniawati ${ }^{3)}$, Tegar Ramadhan ${ }^{4)}$, Elda Rasyida ${ }^{5)}$, \\ Viriana Aulia $^{4)}$, Gita Puspa Indah' ${ }^{2}$, Fikri Alimajid ${ }^{6}$
}

Korespondensi Penulis:

\section{Rifqi Ismiraj \\ E-mail: \\ m.rifqi.ismiraj@unpad.ac.id}

1) Fakultas Peternakan, Universitas

Padjadjaran, Sumedang

2) Program Studi Peternakan,

Universitas Padjadjaran PSDKU

Pangandaran, Pangandaran

3) Program Studi Administrasi

Bisnis, Universitas Padjadjaran

PSDKU Pangandaran, Pangandaran,

4) Program Studi Ilmu Komunikasi,

Universitas Padjadjaran PSDKU

Pangandaran, Pangandaran

5) Program Studi Keperawatan,

Universitas Padjadjaran PSDKU

Pangandaran, Pangandaran

6) Program Studi Perikanan,

Universitas Padjadjaran PSDKU

Pangandaran, Pangandaran

Submitted July 28, 2019

Revised Aug 4, 2020.

Accepted Aug 25, 2020.

\section{Abstract}

Cintaratu Village is located in Parigi District, Pangandaran Regency. This village has great development potential if careful and inclusive planning is carried out. Planning can be done if the decision-maker has the knowledge and awareness of the potential that exists in a location, both natural and sociological potential. Some things that need to be known by decision-makers are the climatology and hydrological conditions because it can affect the success of a development. The method used in this social service is a field survey and literature study. Based on survey results and literature studies, climatology and hydrological conditions map have been successfully created as a database in the Cintaratu Village development effort. In conclusion, Cintaratu Village has great potential, supported by climatological conditions which are quite stable and hydrological conditions that allow for the development of agricultural, livestock, plantation, office, residential, and fishery businesses.

Keywords: Mapping, Climatology, Hydrology, Village

\section{Abstrak}

Desa Cintaratu terletak di Kecamatan Parigi, Kabupaten Pangandaran. Desa ini memiliki potensi pembangunan yang besar jika dilakukan perencanaan yang matang dan inklusif. Perencanaan dapat dilakukan jika pengambil keputusan memiliki pengetahuan dan kesadaran akan potensi yang ada di suatu lokasi, baik potensi alam maupun sosiologis. Beberapa hal yang perlu diketahui oleh pengambil keputusan adalah kondisi klimatologi dan hidrologinya, karena hal tersebut dapat mempengaruhi keberhasilan pembangunan. Metode yang digunakan dalam kegiatan pengabdian ini adalah survey lapangan dan studi pustaka. Berdasarkan hasil survey dan studi pustaka, peta kondisi klimatologi dan hidrologi telah berhasil dibuat sebagai basis data dalam upaya pembangunan Desa Cintaratu. Sebagai kesimpulan, Desa Cintaratu memiliki potensi yang besar, didukung oleh kondisi klimatologi yang sukup stabil dan kondisi hidrologi yang memungkinkan untuk dibangunnya usaha pertanian, peternakan, perkebunan, perkantoran, pemukiman, dan perikanan.

Kata Kunci: pemetaan, klimatologi, hidrologi, desa.

\section{Pendahuluan}

Kabupaten Pangandaran adalah kabupaten baru (dimekarkan pada 2012) yang terletak di wilayah tenggara Jawa Barat (Gambar 1). Beberapa peneliti menyebut bahwa Kab. Pangandaran memiliki potensi yang sangat baik dalam hal pariwisata, pertanian, dan perikanan (Rosyidie, 2010; Rahmafitria et al., 2017; Apriliani et al., 2019). Potensi yang tinggi perlu dipersiapkan untuk pengembangannya. Dengan kata lain, proses 
pembangunan perlu didasari oleh perancanaan yang matang dan inklusif. Inklusivitas dapat diwujudkan dengan pembangunan yang dimulai dari komponen kecil dari sebuah kabupaten, yaitu desa. Salah satu desa yang ditengarai memiliki potensi perkembangan yang pesat adalah Desa Cintaratu yang terletak di Kecamatan Parigi.

Desa Cintaratu terletak di sebelah utara Kecamatan Parigi. Berdasarkan laman daring Desa Cintaratu (https://www.cintaratu.desa.id/geografis/), desa ini memiliki luas 1.029 ha, dengan ketinggian rata-rata 119 meter dari permukaan laut. Desa ini memiliki topografi wilayah yang berbukit sebesar $90 \%$, memiliki curah hujan rata-rata $200 \mathrm{~mm} /$ tahun, dan suhu udara yang berkisar pada $32-34^{\circ} \mathrm{C}$. Proporsi wilayah terbesar yang ada di desa ini merupakan wilayah persawahan/ladang (288,62 ha) dan wilayah pemukiman/perumahan (200 ha).

Desa Cintaratu memiliki potensi pembangunan yang tinggi. Selain memiliki beberapa objek wisata seperti Bukit Jojogan (Tresna and Nirmalasari, 2018; Bakti et al., 2019), juga terdapat objek wisata lain seperti lokasi arung jeram Citumang dan Santirah. Pembangunan perlu didasari oleh perencanaan yang matang dan berbasis kepada profil dan karakteristik lokasi. Perencanaan dapat dilakukan jika pengambil keputusan memiliki pengetahuan dan kesadaran akan potensi yang ada di suatu lokasi, baik potensi alam maupun sosiologis.

Beberapa hal yang perlu diketahui oleh pengambil keputusan adalah kondisi klimatologi dan hidrologi yang ada di suatu lokasi, dalam hal ini yaitu di Desa Cintaratu, Kec. Parigi, Kab. Pangandaran. Baik kondisi klimatologi maupun hidrologi dapat mempengaruhi keberhasilan pembangunan. Suwarto (2011), Becken et al. (2014), Ciervo et al. (2017) dan Salik et al. (2015) melaporkan bahwa keramaian dan kondisi sosio-ekonomi destinasi wisata di Pantai Pangandaran dipengaruhi oleh iklim secara signifikan. Belajar dari laporan tersebut, maka kondisi klimatologis dan hidrologis perlu dipetakan agar secara signifikan dapat mendukung pembangunan yang cepat, tepat, dan efisien.

Data klimatologis biasanya terdiri atas curah hujan, angin, dan temperatur. Sedangkan data hidrologis biasanya memuat jaringan sungai, danau, imbuhan air tanah, mata air (air permukaan) dan cekungan air tanah, akuifer (air tanah). Lebih jauh dari itu, data yang diperlukan untuk persiapan pembangunan juga meliputi potensi sumberdaya air; serta daerah rawan bencana di Desa Cintaratu.
Pengumpulan data perlu dilakukan untuk membangun profil desa, khususnya dalam aspek klimatologis dan hidrologis. Jika profil klimatologis dan hidrologis desa telah terbentuk, maka pemanfaatan lingkungan akan tepat guna dan tidak bersifat spekulatif. Tingkat ketepat-gunaan pemanfaatan lingkungan akan berujung kepada minimalisasi kerusakan lingkungan dan pencemaran. Masyarakat yang terdampak pembangunan akan tidak merasa terganggu, bahkan diharapkan akan ikut mendukung peningkatan sosio-ekonominya. Lebih jauh lagi, dengan terbentuknya profil klimatologis dan hidrologis, antisipasi dan mitigasi terhadap bencana diharapkan dapat menjadi lebih komprehensif.

Sejauh ini, informasi-informasi tersebut belum diperoleh secara komprehensif pada kasus di Desa Cintaratu, Kec. Parigi, Kab. Pangandaran. Oleh karenanya, dirasa perlu untuk merancang dan merumuskan solusi atas kesenjangan pengetahuan tersebut. Sebagai usaha untuk penyelesaian masalah, maka kegiatan pengabdian kepada masyarakat ini dirasa perlu untuk dilakukan.

\section{Materi dan Metode Pelaksanaan}

Kegiatan pengabdian kepada masyarakat ini dilakukan dengan dua metode pengumpulan data, yaitu:

1. Survey

Metode pertama yang digunakan dalam kegiatan ini adalah survey. Survey meliputi wawancara kepada para tokoh masyarakat setempat, pelaku usaha berbasis iklim (petani dan peternak), serta pemerintah desa mengenai kondisi klimatologis dan siklus hidrologis di Desa Cintaratu, Kec. Parigi, Kab. Pangandaran. Survey melibatkan para mahasiswa peserta KKNM Integratif. Hasil survey dianalisis secara deskriptif sebagai testimoni di dalam artikel ini dan diejawantahkan menjadi bentuk peta. Sebagai langkah verifikasi data hasil survey, maka kami menggunakan alat penanda global positioning system (GPS), agar titik lokasi sumber air dapat lebih mudah untuk dipetakan.

Survey juga dilakukan kepada lembaga pemerintah Kabupaten Pangandaran, divisi lingkungan hidup sebagai pencatat dan penyedia data klimatologis dan siklus hidrologis. Kemudian data yang dihimpun akan dianalisis dan disusun menjadi sebuah peta, yang bisa dimanfaatkan dalam kegiatan pengelolaan pembangunan desa.
2. Kajian Pustaka 
Kajian pustaka dilakukan untuk memperkaya data yang telah dihimpun melalui metode survey. Kajian pustaka juga dimaksudkan untuk membandingkan validitas data yang dihimpun dengan pustaka yang telah tersedia. Sumber-sumber pustaka meliputi artikel ilmiah dan data real-time dari lembaga yang berwenang melakukan pengukuran klimatologis di Kabupaten Pangandaran, baik secara luring maupun daring.

\section{Hasil dan Pembahasan}

\section{Gambaran Klimatologi}

Kabupaten Pangandaran mempunyai iklim tropis, suhu rata-rata berkisar antara $26^{\circ} \mathrm{C}-27^{\circ} \mathrm{C}$ dengan suhu minimum $24^{\circ} \mathrm{C}$ dan suhu maksimum $20^{\circ} \mathrm{C}$. Kelembaban udara bervariasi antara $85 \%$ hingga $89 \%$. Curah hujan berkisar antara 1500 $1400 \mathrm{~mm} /$ tahun. Hampir sepanjang tahun mengalami hujan kecuali bulan Juni, Juli dan Agustus.

Dikarenakan keterbatasan data spesifik mengenai Kabupaten Pangandaran Khususnya Desa Cintaratu, maka data curah hujan menggunakan data Kabupaten terdekat, yaitu Kabupaten Ciamis dengan menggunakan stasiun pengamatan hujan terdekat yaitu Stasiun Padaherang, Rata-rata curah hujan selama tahun 2006-2012 Curah hujan tertinggi terjadi pada bulan Desember sebesar 285,8 (mm) dan terendah terjadi pada bulan Agustus sebesar 24,32 (mm; Tabel 1; Tabel 2). Berdasarkan klasifikasi iklim menurut Schmidt-Ferguson, Kabupaten Pangandaran pada umumnya mempunyai tipe iklim C.

Tabel 1

Tabel Curah Hujan Kecamatan Parigi 2018

\begin{tabular}{|l|c|c|}
\hline \multicolumn{1}{|c|}{ Bulan } & $\begin{array}{c}\text { Hari Hujan } \\
\text { (Hari) }\end{array}$ & $\begin{array}{c}\text { Curah Hujan } \\
(\mathrm{mm})\end{array}$ \\
\hline Januari & 9 & 204,5 \\
\hline Februari & 14 & 675 \\
\hline Maret & 20 & 404 \\
\hline April & 17 & 455,5 \\
\hline Mei & 10 & 192 \\
\hline Juni & 16 & 485 \\
\hline Juli & 0 & 0 \\
\hline Agustus & 0 & 0 \\
\hline September & 9 & 167 \\
\hline Oktober & 14 & 286 \\
\hline November & 16 & 980 \\
\hline Desember & 14 & 289 \\
\hline Jumlah/Total & $\mathbf{1 3 9}$ & $\mathbf{4 . 1 3 8}$ \\
\hline
\end{tabular}

Sumber: Badan Pusat Statistik Kabupaten Ciamis
Tabel 2

Curah Harian dan Curah Hujan Kecamanatan Parigi Tahun 2014-2015

\begin{tabular}{|c|c|c|c|c|}
\hline \multicolumn{4}{|c|}{$\begin{array}{r}\text { Jumlah Hari Hujan dan Curah Hujan Menurut Kecamatan di } \\
\text { Kabupaten Pangandaran Tahun 2014-2015 }\end{array}$} \\
\hline \multirow{2}{*}{ Kecamatan } & \multicolumn{2}{|c|}{ Hari Hujan (Hari) } & \multicolumn{2}{c|}{ Curah Hujan } \\
\cline { 2 - 5 } & 2014 & 2015 & 2014 & 2015 \\
\hline Parigi & 160,00 & 170,00 & 3163,00 & 3163,00 \\
\hline
\end{tabular}

Sumber: Dinas Pertanian Kabupaten Pangandaran

\section{Gambaran Hidrologi}

Kedalaman muka air tanah di Desa Cintaratu salah satunya dipengaruhi oleh kondisi geografi, semakin dalam muka air tanah disuatu lokasi, semakin tinggi pula kedudukan geografis lokasi tersebut. Dusun dengan lokasi geografi tertinggi yaitu dusun Gunung Tiga dengan kedalaman muka air tanah rata rata yaitu 15,6 $\mathrm{m}$ dan dusun dengan lokasi yang terendah adalah dusun bontos yang memiliki rata rata muka air tanah $6,8 \mathrm{~m}$. Kami mendapatkan data dengan berkunjung ke warga di 34 RT dan melakukan observasi ke 7 mata air yang ada di desa Cintaratu.

\section{Peta Hidrologi}

Berdasarkan hasil pengumpulan data di lapangan mengenai pemetaan sumber mata air baik mata air alami maupun mata air buatan (sumur), maka dapat diperoleh peta hidrologi seperti yang digambarkan dalam Gambar 1. Berdasarkan peta hidrologinya, dapat diketahui bahwa sebagian besar mata air berupa sumur buatan yang berada di lokasi residensial sebagai penyedia kebutuhan air dasar bagi masyarakat desa Cintaratu. Namun lebih jauh dari itu, terdapat beberapa mata air yang selain memiliki potensi ketersediaannya yang stabil, juga memiliki potensi pariwisata, seperti mata air (berupa air terjun) Jojogan. Keberadaan sumber mata air yang memiliki potensi pariwisata tersebut sangat berpeluang besar untuk meningkatkan kesejahteraan masyarakat Desa Cintaratu apabila dapat dikelola dengan baik.

\section{Kebermanfaatan}

Kegiatan ini bertujuan untuk memperkaya informasi mengenai gambaran klimatologis dan hidrologis Desa Cintaratu, Kec. Parigi, Kab. Pangandaran. Output berupa peta diharapkan akan bermanfaat dalam pembangunan desa. Potensi Desa Cintaratu diharapkan dapat diakselerasi prosesnya 


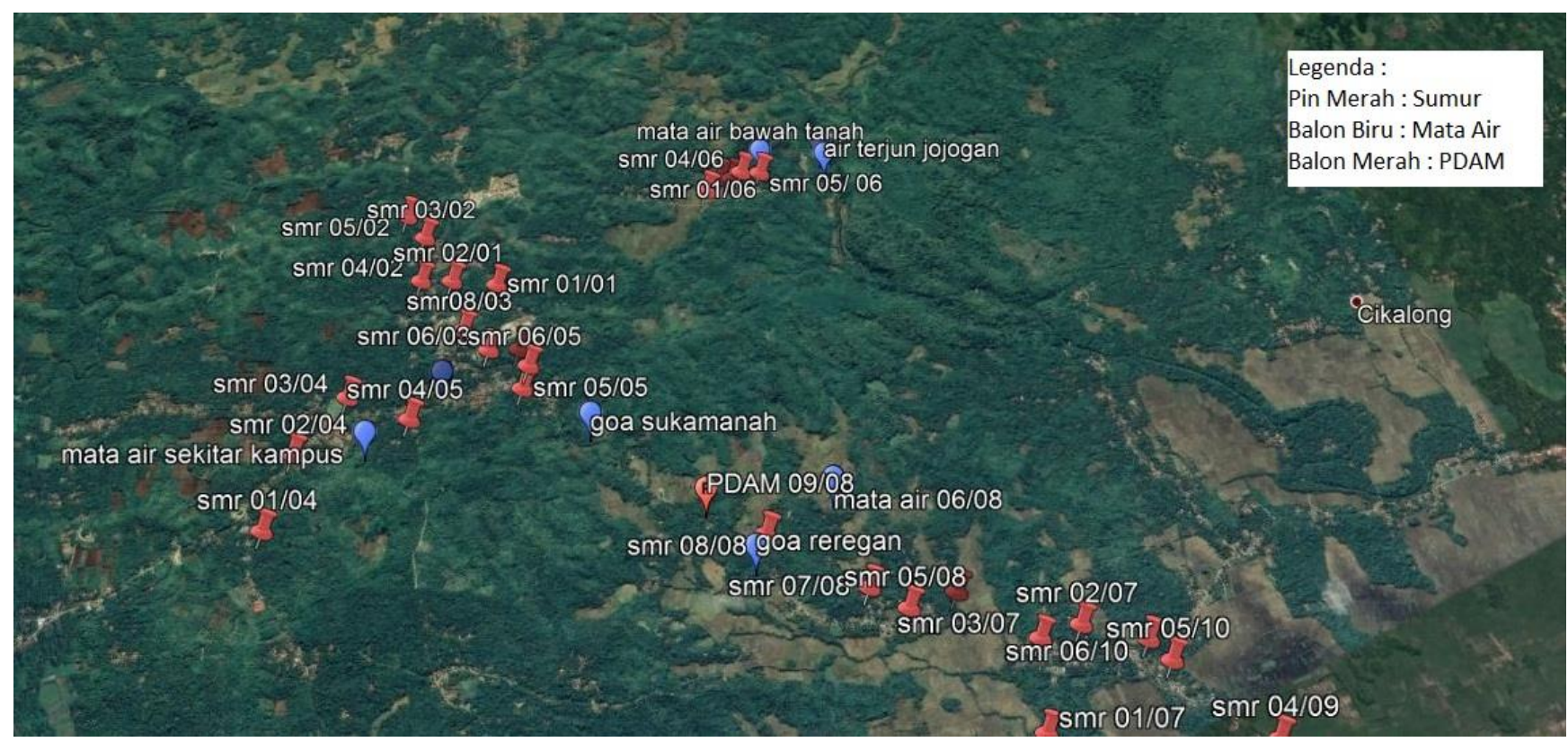

Gambar 1. Peta Hidrologi Desa Cintaratu, Kecamatan Parigi, Kabupaten Pangandaran

jika terdapat basis data yang menjelaskan potensi beserta rekomendasinya.

Selain daripada itu, proses penghimpunan data yang dilaksanakan secara survey menggambarkan data temuan di lapangan yang bersifat perlu verifikasi. Oleh karenanya, penggunaan alat bantu seperti GPS diperlukan agar proses penerjemahan data hasil survey menjadi sebuah peta dapat dilakukan dengan lebih mudah dan akurat. Meskipun demikian, proses penggalian data untuk aspek klimatologis belum dapat dilaksanakan secara optimal dikarenakan adanya keterbatasan stasiun pengukur cuaca dan iklim di Kabupaten Pangandaran, khususnya dalam skala desa atau kecamatan. Hal ini menjadi dasar untuk rekomendasi pengadaan stasiun cuaca di Kabupaten Pangandaran dalam skala desa dan kecamatan agar data klimatologis yang dapat digali menjadi lebih detail dan spesifik.

\section{Kesimpulan}

Pemetaan dan penghimpunan data klimatologis dan hidrologis di Desa Cintaratu telah berhasil dilaksanakan. Berdasarkan data yang diperoleh, dapat disimpulkan bahwa terdapat potensi yang tinggi di Desa Cintaratu untuk dilaksanakan pembangunan di bidang usaha pertanian, peternakan, dan pariwisata. Meskipun begitu, terdapat keterbatasan seperti tidak adanya stasiun cuaca di Kabupaten Pangandaran yang idealnya dapat menyediakan data yang lebih detail dan spesifik.
Oleh karenanya, disarankan bagi pemegang kebijakan yang berwenang untuk mengadakan stasiun pencatat cuaca dan iklim di Pangandaran yang mencakup pencatatan data iklim di setiap desa atau kecamatan di Kabupaten Pangandaran, sehingga data yang dapat diamati lebih detail dan spesifik.

\section{Daftar Pustaka}

Apriliani, I. M., A. M. A. Khan, L. P. Dewanti, A. Rizal, H. Hamdani, and C. Oktavera. 2019. Hanging Ratio Gillnets on Different Mesh Sizes for Mackerel (Scomberomorus commerson): A Case of Pangandaran Regency, Indonesia. Asian J. Fish. Aquat. Res.:1-7.

Bakti, I., S. Sumartias, T. Damayanti, and A. R. Nugraha. 2019. Pelatihan Storytelling dalam Membangun Ekonomi Kreatif Bidang Pariwisata di Desa Cintaratu Kecamatan Parigi Kabupaten Pangandaran. J. Bakti Masy. Indones. 1.

Becken, S., C. Zammit, and J. Hendrikx. 2014. Developing Climate Change Maps for Tourism: Essential Information or Awareness Raising? J. Travel Res. 54:430-441 Available at https://doi.org/10.1177/0047287514528286.

Ciervo, F., G. Rianna, P. Mercogliano, and M. N. Papa. 2017. Effects of climate change on shallow landslides in a small coastal catchment in southern Italy. Landslides 14:1043-1055 Available at https://doi.org/10.1007/s10346-016-0743-1.

Rahmafitria, F., R. M. Wirakusuma, and A. Riswandi. 2017. Development of Tourism Potential in 
Watersports Recreation, Santirah River, Pangandaran Regency, Indonesia. PEOPLE Int. J. Soc. Sci. 3 Available at https://grdspublishing.org/index.php/people/articl e/view/442.

Rosyidie, A. 2010. The Influence of Climate Factors on Tourist Visits in Pangandaran Coastal Tourism Area. ASEAN J. Hosp. Tour. 9:87-100.

Salik, K. M., S. Jahangir, W. ul Z. Zahdi, and S. ul Hasson. 2015. Climate change vulnerability and adaptation options for the coastal communities of Pakistan. Ocean Coast. Manag. 112:61-73 Available at http://www.sciencedirect.com/science/article/pii/S 0964569115001209.

Suwarto, T. 2011. Pengaruh Iklim dan Perubahannya Terhadap Destinasi Pariwisata Pantai Pangandaran. J. Reg. City Planning; Vol 22, No 1 Available at http://journals.itb.ac.id/index.php/jpwk/article/vie w/4131/2217.

Tresna, P. W., and H. Nirmalasari. 2018. Sustainable Competitive Advantage Strategies of Tourism Products in Pangandaran District. Rev. Integr. Bus. Econ. Res. 7:34-47. 